\title{
Ectopic Cushing Syndrome Due to Colon Cancer With Dual Morphology
}

\author{
Bryndis Baldvinsdottir ${ }^{\mathrm{a}}$, Jon G. Jonasson ${ }^{\mathrm{b}, \mathrm{c}}$, Uggi P. Agnarsson ${ }^{\mathrm{c}, \mathrm{d}}$, Helga A. Sigurjonsdottir ${ }^{\mathrm{c}, \text { e, f }}$
}

\begin{abstract}
We report a case of colon cancer, and the most interesting presentation was Cushing's syndrome (CS). A 72-year-old woman was diagnosed with CS when admitted to hospital because of NSTEMI and heart failure. The patient succumbed to her illness only 4 weeks after presentation. The colon cancer was a combined adenocarcinoma and small cell carcinoma, solely the latter component responsible for producing adrenocorticotropin hormone (ACTH).
\end{abstract}

Keywords: Colon cancer; Cushing's syndrome; Ectopic Cushing's syndrome; ACTH; Small cell cancer; Adenocarcinoma; Hypertension; Hypokalemia

\section{Introduction}

Ectopic secretion of adrenocorticotropin hormone (ACTH) is a rare cause of Cushing's syndrome (CS), and when diagnosed the primary tumor is most often lung cancer. Colon cancer as a cause is extremely rare in spite of being among the most common malignancies in the general population.

To our knowledge, there are only 10 [1-3] reported cases of ACTH-secreting colon cancer cases in the literature.

\section{Case Report}

A 72-year-old Caucasian woman was admitted to the cardi-

Manuscript accepted for publication December 15, 2014

a Department of Medicine, Landspitali University Hospital, Reykjavik, Iceland bepartment of Pathology, Landspitali University Hospital, Reykjavik, Iceland

${ }^{\mathrm{c}}$ Faculty of Medicine, University of Iceland, Reykjavik, Iceland

dDepartment of Cardiology, Landspitali University Hospital, Reykjavik, Iceland

eDepartment of Endocrinology, Landspitali University Hospital, Reykjavik, Iceland

${ }^{f}$ Corresponding Author: Helga A. Sigurjonsdottir, Department of Endocrinology and Metabolism, Landspitali University Hospital 108, Reykjavik, Iceland. Email: helgaags@1sh.is

doi: http://dx.doi.org/10.14740/jem263e ology ward at Landspitali University Hospital in Reykjavik, Iceland (LSH) with NSTEMI, hypertension and heart failure following a 7-day stay at a primary hospital (HSU). She had been admitted to HSU with increased fatigue, ankle edema and resistant hypertension. There she was found to be hyperglycemic, hypokalemic and hypertensive. Medical treatment was without success. At arrival to LSH she had hypertension (169/66 mm Hg), hyperglycemia (serum glucose level 23.6 $\mathrm{mmol} / \mathrm{L}$ ) and profound hypokalemia (serum potassium levels $2.0 \mathrm{mmol} / \mathrm{L}$ ), despite ongoing potassium-sparing anti-hypertensive treatment (enalapril $10 \mathrm{mg}$ daily, losartan $50 \mathrm{mg}$ daily and spironalactone $50 \mathrm{mg}$ daily).

She had cushingoid appearance with central obesity, moon-face and thinning of the skin, but not stria or hirsutism. The patient had been treated for hypertension for several years with no history of hypokalemia. Serum levels of potassium 2 months earlier were normal. She complained of muscle weakness. Serum cortisol level, measured at $16: 30 \mathrm{pm}$ was 2,613 nmol/L (reference: 170 - $700 \mathrm{nmol} / \mathrm{L}$ ).

Morning serum cortisol levels and plasma ACTH were 3,113 nmol/L (reference: 170 - $700 \mathrm{nmol} / \mathrm{L}$ ) and $769 \mathrm{ng} / \mathrm{L}$ (reference: 0 - $46 \mathrm{ng} / \mathrm{L}$ ), respectively. After low-dose overnight, dexamethason suppression test (DST), with $1 \mathrm{mg}$ dexamethasone given orally at 23:00 pm, serum cortisol level at 8:00 am was not suppressed, 3,416 nmol/L. A 2-day low dose DST ( 0.5 mg every $6 \mathrm{~h}$ for $48 \mathrm{~h}$ ) was performed without suppression of morning serum levels of cortisol that were $4,675 \mathrm{nmol} / \mathrm{L}$ at the start of the test, $4,679 \mathrm{nmol} / \mathrm{L}$ after $24 \mathrm{~h}$ DST and $4,919 \mathrm{nmol} / \mathrm{L}$ after $48 \mathrm{~h}$ suppression. Plasma ACTH level was $4,658 \mathrm{ng} / \mathrm{L}$ (reference: 0 - $46 \mathrm{ng} / \mathrm{L}$ ) $24 \mathrm{~h}$ after the 2-day DST.

Computed tomography (CT) of the abdomen showed a solid tumor of uncertain etiology at the recto-sigmoid junction and widespread metastases in the liver and lymph nodes.

$\mathrm{A}$ CT of the thorax showed metastases in the lungs, and magnetic resonance imaging (MRI) of the pituitary gland was negative.

The $24 \mathrm{~h}$ urine sample for 5-HIAA, adrenalin, noradrenalin, dopamin, VMA, metanephrin and normetanephrin, was normal.

During the hospital stay, the patient needed high doses of potassium supplementation as well as anti-hypertensive and insulin treatment. Over the course of several days the patient's state worsened. She passed away only 26 days after her first admittance to LSH and 33 days after she was first admitted 


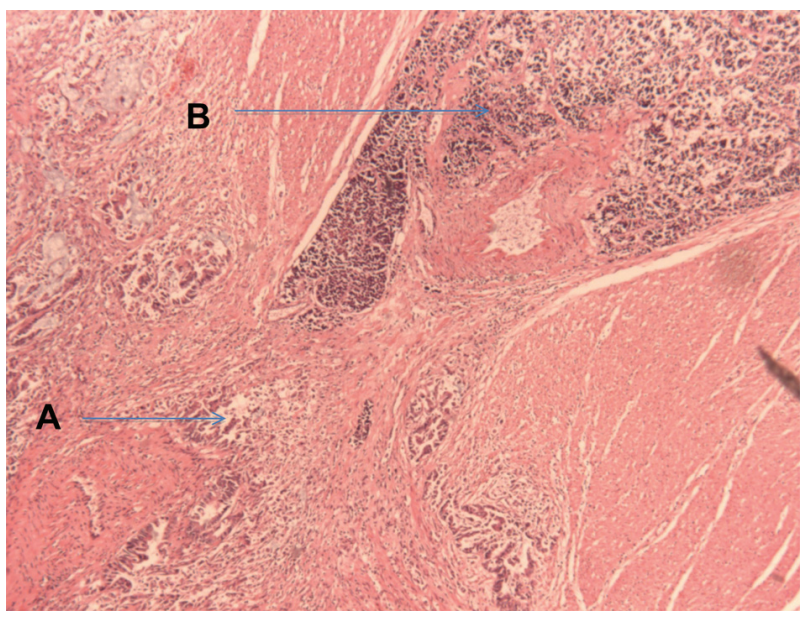

Figure 1. Biopsy from primary tumor in colon. On the left is a classic adenocarcinoma of colon $(\mathrm{A})$ and on the right a small cell carcinoma (B).

to the primary hospital. Autopsy revealed a primary tumor in the sigmoid colon. The tumor proved to be a combined adenocarcinoma and small cell carcinoma. The adenocarcinoma component was a conventional colonic type adenocarcinoma. The small cell (neuroendocrine carcinoma) component had the same appearance as the well known small cell anaplastic carcinoma of the lung. Immunohistochemical stain of the primary tumor showed the adenocarcinoma to be positive for CK20. The small cell carcinoma was positive for neuron specific enolase (NSE), chromogranin, synaptophysin and ACTH (in less than $5 \%$ of the SCC tumor cells) (Fig. 1). Widespread metastases were present in the body, but solely from the small cell carcinoma component of the tumor. Lymph node metastases were detected in the pericolonic, peripancreatic, para-aortical and mediastinal lymph nodes. Massive metastases were also present in the liver and lungs. No abnormal growth was detected in the bone marrow and the megakaryocytes were normal. An immunohistochemical stain for ACTH was performed on one of the metastases, and this illustrated positive tumor cells as well as in the primary tumor.

\section{Discussion}

We present a very unusual type of colon cancer presenting with CS. The explosive progression of the disease is alarming. The patient passed away only 33 days following admission to a hospital. Two months earlier she was normokalemic, but dur- ing the hospital period she needed large doses of potassium supplements by infusion. The autopsy results support the clinical and radiologic findings. The colon cancer was of a very unusual morphologic type showing both conventional colonic adenocarcinoma, as well as but predominantly a small cell carcinoma histology. The explosive elevation of ACTH secretion from 769 to $4,658 \mathrm{ng} / \mathrm{L}$ in 17 days, and the resistant hypertension, hyperglycemia and hypokalemia give the impression that the tumor was growing at an extremely fast rate. Unfortunately the first plasma ACTH levels did not arrive until 1 week after they were taken. Retrospectively, there were some alarming clinical signs during the hospital admission, i.e., the extreme hypertension and hypokalemia. In spite of that, the extreme progress of the disease and the profound metastatic growth of the tumor indicate that earlier diagnoses during the hospital stay would not have changed the outcome. The symptoms of hypercortisolism were the clinical signs of this malignant colon cancer, and possibly the myocardial infarct and heart failure were secondary to that. Apart from a similar case [1] in 2010 there has been no report on this kind of tumor in the English literature in recent years. A thorough literature search for similar cases was performed and revealed only 10 previously reported cases of CS caused by ectopic ACTH producing colon cancer. Another astonishing factor about this case is that the primary colon cancer had dual morphology, both adenocarcinoma and small cell carcinoma. Neuroendocrine tumors of the colon are extremely rare, estimated less than $1 \%$ of colorectal cancers with bad overall outcome. They behave aggressively as most patients have metastases at the time of diagnosis [4, 5].

\section{References}

1. Sehgal R, Mchayleh W, Reider J, et al. Adenocarcinoma of Colon Presenting As Cushing's syndrome. Journal of Clinical Oncology. 2010;28:126-127.

2. Miura K, Demura H, Sato E, Sasano N, Shimizu N. A case of ACTH-secreting cancer of the colon. J Clin Endocrinol Metab. 1970;31(5):591-595.

3. Anthoney DA, Dunlop DJ, Connell JM, Kaye SB. Colonic adenocarcinoma associated ectopic ACTH secretion: a case history. Eur J Cancer. 1995;31A(12):2109-2112.

4. Bernick PE, Klimstra DS, Shia J, Minsky B, Saltz L, Shi W, Thaler H, et al. Neuroendocrine carcinomas of the colon and rectum. Dis Colon Rectum. 2004;47(2):163-169.

5. Jung SH, Kim HC, Yu CS, Chang HM, Ryu MH, Lee JL, Kim JS, et al. [Clinicopathologic characteristics of colorectal neuroendocrine tumor]. Korean J Gastroenterol. 2006;48(2):97-103. 